\title{
AgNP-PVP-meglumine antimoniate nanocomposite reduces Leishmania amazonensis infection in macrophages
}

\author{
Ana Patricia Cacua Gélvez¹,2, José Antonio Picanço Diniz Junior ${ }^{1}$, Rebecca Thereza Silva Santa Brígida ${ }^{1,2}$ and \\ Ana Paula Drummond Rodrigues ${ }^{1 *}$
}

\begin{abstract}
Background: Leishmaniasis is an infectious disease caused by parasites of the genus Leishmania and presents different clinical manifestations. The adverse effects, immunosuppression and resistant strains associated with this disease necessitate the development of new drugs. Nanoparticles have shown potential as alternative antileishmanial drugs. We showed in a previous study the biosynthesis, characterization and ideal concentration of a nanocomposite that promoted leishmanicidal activity. In the present study, we conducted a specific analysis to show the mechanism of action of AgNP-PVP-MA (silver nanoparticle-polyvinylpyrrolidone-[meglumine antimoniate (Glucantime $\left.{ }^{\circledast}\right)$ ]) nanocomposite during Leishmania amazonensis infection in vitro.

Results: Through ultrastructural analysis, we observed significant alterations, such as the presence of small vesicles in the flagellar pocket and in the extracellular membrane, myelin-like structure formation in the Golgi complex and mitochondria, flagellum and plasma membrane rupture, and electrodense material deposition at the edges of the parasite nucleus in both evolutive forms. Furthermore, the Leishmania parasite infection index in macrophages decreased significantly after treatment, and nitric oxide and reactive oxygen species production levels were determined. Additionally, inflammatory, and pro-inflammatory cytokine and chemokine production levels were evaluated. The IL-4, TNF- $a$ and MIP-1 a levels increased significantly, while the IL-17 A level decreased significantly after treatment.
\end{abstract}

Conclusions: Thus, we demonstrate in this study that the AgNP-PVP-MA nanocomposite has leishmanial potential, and the mechanism of action was demonstrated for the first time, showing that this bioproduct seems to be a potential alternative treatment for leishmaniasis.

Keywords: AgNP-PVP-MA nanocomposite, Cytokine production, Antileishmanial, Ultrastructural alterations, Leishmaniasis

\footnotetext{
* Correspondence: anarodrigues@iec.gov.br

${ }^{1}$ Evandro Chagas Institute, Secretary of Health Surveillance, Laboratory of Electron Microscopy, Ministry of Health, Av. Almirante Barroso, 492, Marco, Pará 66090-000 Belém, Brazil

Full list of author information is available at the end of the article
}

C C The Author(s). 2021 Open Access This article is licensed under a Creative Commons Attribution 4.0 International License, which permits use, sharing, adaptation, distribution and reproduction in any medium or format, as long as you give appropriate credit to the original author(s) and the source, provide a link to the Creative Commons licence, and indicate if changes were made. The images or other third party material in this article are included in the article's Creative Commons licence, unless indicated otherwise in a credit line to the material. If material is not included in the article's Creative Commons licence and your intended use is not permitted by statutory regulation or exceeds the permitted use, you will need to obtain permission directly from the copyright holder. To view a copy of this licence, visit http://creativecommons.org/licenses/by/4.0/ The Creative Commons Public Domain Dedication waiver (http://creativecommons.org/publicdomain/zero/1.0/) applies to the data made available in this article, unless otherwise stated in a credit line to the data. 


\section{Background}

Leishmaniasis is a parasitic disease and has various clinical manifestations: cutaneous, mucocutaneous and visceral. The complex interactions between the infectious capacity of different species of Leishmania and the immune status of the human host are related to different clinical forms of leishmaniasis; the disease represents a global public health problem [1]. It is estimated that approximately 350 million people live in regions where there is a risk of acquiring infection; 1.3 million new cases are recorded and approximately 20,000 to 30,000 deaths occur each year [1].

In Brazil, American cutaneous leishmaniasis (ACL) caused by parasites of the genus Leishmania is transmitted by sandflies of the genus Lutzomyia [2], and the treatment comprises first-line drugs such as pentavalent antimonials, which, in Brazil, are represented by the antimoniate of $\mathrm{N}$-methylglucamine or meglumine antimoniate [3]. In specific cases or due to a lack of response to antimonial treatment, second-line drugs such as amphotericin B (AMB) and pentamidine are used [4]. Due to the resistance of some Leishmania species to the drugs mentioned above, suppressed immunity and different scenarios of adverse effects in patients when treated with them [5], the search for new treatment criteria and therapeutic alternatives with reduced side effects that improve the effectiveness of traditional methods are studied continuously [6]. Therefore, it is noteworthy that the delivery of therapeutic compounds to specific targets has been one of the problems in the treatment of diseases and that the conventional administration of some drugs is characterized by limited efficacy, low distribution and poor target selectivity $[6,7]$.

In recent years, the tools offered by nanotechnology techniques have been applied to the development of new medicines through the handling of materials and/or nanocomposites due to their electrical, optical, magnetic and physicochemical properties, making them beneficial for medical, physical, optical and electronic applications [7]. With the advent of nanodrug technology, delivery systems based on liposomes, nanoemulsions, micelles and dendrimers conjugated to polymeric nanoparticles, solid lipid nanoparticles, metal nanoparticles, carbon nanotubes and drugs of interest (meglumine antimoniate, amphotericin and miltefosine, among others) $[8,9]$ have shown excellent potential, with antileishmanial activity against Leishmania major [10], Leishmania infantum [11], Leishmania tropica [12], and Leishmania amazonensis [13].

The interaction of nanoparticles with current drugs used in the treatment of leishmaniasis is of great interest for three reasons: 1- dosages currently used to treat leishmaniasis are well known; 2- they have the potential to treat resistant strains; and 3- better therapeutic results could be achieved [6, 7]. Thus, conjugation between compounds has generated positive results in several studies for the control of leishmaniasis, mainly leading to an increased inhibitory action of conjugated drugs against parasites compared to that of the individual drug treatments [12]. Our research group first biosynthesized, optimized, characterized, and demonstrated that the nanocomposite AgNP-PVP-MA reduced, in vitro, the viability of promastigotes and the macrophage infection of amastigotes, without causing cytotoxic effects on mouse macrophages, in vitro. However, we do not know how the AgNP-PVP-MA reacts or acts in the different evolutive forms of Leishmania amazonensis, or even if the nanocomposite could act indirectly to induce an immune response during the macrophage infection. Posteriorly, some additional questions arose from the answers.

\section{Materials and methods preparation of the nanocomposite}

The nanocomposite is a combination of AgNP (100\% stock solution of AgNP) obtained by biological synthesis from Aspergillus flavus culture (size $<10 \mathrm{~nm}$ ) mixed with the polymer PVP (10\%) obtained the AgNP-PVP. After that, the stock solution of Glucantime $(1 \mathrm{mg} / \mathrm{mL})$ was added in the AgNP-PVP solution to obtained the nanocomposite AgNP-PVP-MA with $50 \mu \mathrm{g} / \mathrm{mL}$ as final concentration of MA. To define the appropriate concentration used in the present study, we performed several preliminary biological tests. The process of nanocomposite production and the determination of the ideal concentration for use were detailed in our previous publication [13]. All experiments were performed in accordance with the arrive guidelines.

\section{Biological tests \\ Definition of nanocomposite concentration and reference \\ drug}

During the optimization of the nanocomposite AgNPPVP-MA in previous published research, AgNP, PVP and MA, individually and together, as well as the reference drug amphotericin B were tested at different concentrations, both in macrophage cells and in the promastigote and amastigote forms of the Leishmania amazonensis parasite. Based on these results, the appropriate concentrations were defined, considering the affecting viability of the parasite and the reduced or absent cytotoxicity in macrophages (data not shown). In our preliminary evaluation, as the inhibitory effect in the amastigote forms was lower when the Glucantime ${ }^{\bullet}$ was used as reference drug, we consider the amphotericin $B$ more reliable as a reference drug for comparisons to the nanocomposite effect (data not shown). 


\section{Parasites}

Promastigote forms of Leishmania amazonensis (MHO/ BR/M26361) were obtained in Novy-MacNeal-Nicolle (NNN) medium from the Evandro Chagas Institute Leishmaniasis Program and maintained in RPMI 1640 medium (Sigma-Aldrich ${ }^{\oplus}$, USA) supplemented with $10 \%$ fetal bovine serum (FBS - Gibco ${ }^{\circ}$ Thermo Fisher Scientific, USA) in biological oxygen demand (BOD) at $27{ }^{\circ} \mathrm{C}$.

\section{In vitro macrophage test}

Intraperitoneal macrophages (IPФ) were obtained from 8 - to 10 -week-old BALB/c albino mice. The animals were produced and obtained from the Animal Facility of Evandro Chagas Institute. The animals were euthanized for cell collection by washing the peritoneal cavity, according to the Commission on the Ethics of Animal Experiments of the Evandro Chagas Institute. The aspirated material was concentrated by centrifugation for $10 \mathrm{~min}$ at $2500 \mathrm{~g}$ and at $10{ }^{\circ} \mathrm{C}$. After that, the cells were counted in a Neubauer chamber, and the concentration was adjusted to $2 \times 10^{5} / \mathrm{mL}$. Macrophages were transferred to 24-well culture plates or $75 \mathrm{~cm}^{2}$ cell culture flasks incubated at $37{ }^{\circ} \mathrm{C}$ in a humidified atmosphere containing $5 \% \mathrm{CO}_{2}$ for $1 \mathrm{~h}$ for cell adhesion. After this period, cells were washed with sterile phosphate-buffered saline (PBS), pH 7.2, to remove nonadherent cells, and Dulbecco's modified Eagle's medium (DMEM - Sigma-Aldrich ${ }^{\oplus}$, USA), pH 7.2, with penicillin/ streptomycin and supplemented with $10 \%$ FBS. Cells were maintained at $37{ }^{\circ} \mathrm{C}$ in $5 \% \mathrm{CO}_{2}$ atmosphere for $24 \mathrm{~h}(\mathrm{~h})$.

\section{Anti-amastigote activity}

To determine the infection rate in macrophages, these cells were cultured as specified in the previous section on cover slips on the bottom of the culture plate and allowed to interact with Leishmania amazonensis promastigotes in a ratio of $1: 10$ for $3 \mathrm{~h}$ at $35^{\circ} \mathrm{C}$ and an atmosphere of $5 \% \mathrm{CO}_{2}$. Then, the supernatant was discarded, and DMEM with $10 \%$ FBS was added and incubated for $24 \mathrm{~h}$ under the conditions mentioned. Subsequently, infected cells were treated for $24 \mathrm{~h}$ with AgNP-PVP-MA nanocomposite with the concentration already described, under the same temperature and atmosphere conditions as those described above. As a positive control, amphotericin $\mathrm{B}$ was used at a concentration of $0.5 \mu \mathrm{g} / \mathrm{mL}$, and infected cells without treatment were used as a negative control. After the treatment period, the supernatants were collected and stored in microtubes in a freezer $\left(-70{ }^{\circ} \mathrm{C}\right)$ for further nitrite and cytokine evaluations. Subsequently, the coverslips were washed with PBS and fixed with $3 \%$ formaldehyde for $30 \mathrm{~min}$. Cells were incubated for 10 min with DAPI (Molecular Probes Invitrogen ${ }^{\oplus}$, USA) for nuclei detection (1:100) and with Alexa Fluor ${ }^{\ominus} 594$ phalloidin (Molecular Probes Invitrogen ${ }^{\oplus}$, USA) for actin filaments (1:200) and were subsequently mounted on glass slides using ProLong Gold ${ }^{\oplus}$ Antifade reagent (Molecular Probes Invitrogen ${ }^{\bullet}$ USA). Noninfected and infected cells were counted in random fields using an Axio Scope A1, Carl Zeiss Microscopy, using ZENLite software. At least 100 infected macrophages were counted, and the number of parasites was determined by examining three coverslips for each treatment. The results are expressed as an infectivity index (II) according to Eq. (1) $[13,14]$ :

Infectivity Index $(I I)=\frac{\% \text { Infected macrophages } \times \text { Parasites internalized } / \text { Cell }}{\text { Total number of macrophages }}$

\section{Ultrastructural analysis of Leishmania amazonensis}

Promastigote forms of Leishmania amazonensis were cultivated in culture bottles at a parasite concentration of $1 \times 10^{6} / \mathrm{mL}$ and treated for $96 \mathrm{~h}$, while intracellular cultures were treated for $24 \mathrm{~h}$; both developmental forms of the parasite were treated with AgNP-PVP-MA nanocomposite in the concentration and conditions described above. After the treatment period, the samples were processed for evaluation by scanning electron microscopy (SEM) and transmission electron microscopy (TEM). The samples were fixed for one hour at room temperature in a solution containing $2.5 \%$ glutaraldehyde, $4 \%$ formaldehyde and $2.5 \%$ sucrose in Phem buffer (composed of $0.235 \mathrm{~g}$ of $\mathrm{MgCl}_{2}, 2.61 \mathrm{~g}$ of $\mathrm{KCl}, 1.9 \mathrm{~g}$ of EGTA, $2.6 \mathrm{~g}$ of HEPES, and 10.4 $\mathrm{g}$ of PIPES in $250 \mathrm{ml}$ of Milli-Q water at $\mathrm{pH}$ 7.2). Subsequently, the cells were washed in $0.1 \mathrm{M}$ cacodylate buffer and incubated for $1 \mathrm{~h}$ at room temperature in a solution containing $1 \%$ osmium tetroxide and $0.8 \%$ potassium ferrocyanide. Then, for SEM, dehydration was performed in an increasing series of ethanol concentrations for $10 \mathrm{~min}$, and samples were dried at the critical point (Modelo K 850 - Mark EMITCH) using $\mathrm{CO}_{2}$. The samples were fixed in an appropriate support (stub) using carbon tape and metalized (Metallizer Emitech K 550 - England) with a gold film approximately $2 \mathrm{~nm}$ thick for further evaluation with a Zeiss LEO 1450VP SEM. For TEM analyses, cells were fixed and post-fixed as described above, stained with $1 \%$ uranyl, and dehydrated in an increasing series of acetone concentrations for $10 \mathrm{~min}$. After dehydration, cells were slowly impregnated with Epon resin at concentrations of 2:1, 1:1, 1:2 (acetone: Epon) and finally pure Epon for $12 \mathrm{~h}$. Subsequently, the material was incubated in pure Epon + DMP30 for $6 \mathrm{~h}$, followed by polymerization at $60{ }^{\circ} \mathrm{C}$ for $48 \mathrm{~h}$. The polymerized blocks were cut by 
ultramicrotomy and contrasted with lead citrate for 3 min for further evaluation with a Zeiss EM 900 TEM.

\section{Nitrite quantitation}

Nitric oxide production was estimated by determining the concentration of nitrite $\left(\mathrm{NO}_{2}^{-}\right)$present in the supernatant of the macrophage cultures infected by stationary phase promastigotes after treatment with the AgNPPVP-MA nanocomposite at the concentration described above for $24 \mathrm{~h}$ using the Griess method [15]. The culture supernatant was collected, and nitrite production was evaluated using a Griess Reagent Kit (Molecular Probes Invitrogen ${ }^{\oplus}$, USA) for nitrite quantitation according to the methods described [16] and to the manufacturer's instructions. The nitrite concentration was determined using dilutions of sodium nitrite $\left(\mathrm{NaNO}_{2}\right)$ to create a standard curve, and the results were expressed in micromolar $(\mu \mathrm{M})$.

\section{Measurement of reactive oxygen species levels}

Macrophage cultures $\left(5 \times 10^{5} / \mathrm{mL}\right)$ infected with Leishmania amazonensis $\left(5 \times 10^{6} / \mathrm{mL}\right)$ under the same conditions as described above were treated or untreated with AgNP-PVP-MA nanocomposite in the concentration described above for $24 \mathrm{~h}$. After that, the cells were washed with $\mathrm{PBS}, \mathrm{pH} 7.2$, and subsequently incubated with 5.0 $\mu \mathrm{M}$ CellROX ${ }^{\oplus}$ Green reagents (Molecular Probes Invitrogen $^{\circ}$, USA) in PBS for oxidative stress detection, according to the manufacturer's instructions. After a 30-min incubation in the dark at $37{ }^{\circ} \mathrm{C}$ and $5 \% \mathrm{CO}_{2}$, the cells were washed with PBS, $\mathrm{pH} 7.2$, and fixed in 3.7-4.0\% paraformaldehyde for $15 \mathrm{~min}$, followed by washing in PBS. Cells without AgNP-PVP-MA nanocomposites were used as a negative control. Fluorescence was measured using a VICTOR Multilabel Plate Reader X fluorometer at $485 \mathrm{~nm}$ and $520 \mathrm{~nm}$ for excitation and emission, respectively. The results were expressed as optical density (OD).

\section{Detection and quantification of cytokines and chemokines}

Cytokines present in the supernatants of Leishmania-infected cultures after infection and treatment for $24 \mathrm{~h}$ with AgNP-PVP-MA nanocomposite in the concentration already described were quantified by flow cytometry. The cytokines IL-2, IL-4, IL-6, IFN- $\gamma$, IL-10, IL-17 A and TNF- $\alpha$ were measured using BD Cytometric Bead Array (CBA) - Cytokine Kit Mouse Th1/Th2/Th17; the cytokine IL-1 $\beta$, GM-CSF and the chemokines MCP-1, MIP- $1 \alpha$ and RANTES were measured using BD CBA Mouse Flex Set according to the manufacturer's instructions. The data were obtained with BD FACSCanto II using FACSDiva software (BD Biosciences, USA), and analysis was performed in FCAP Array 3.0. The results were expressed as $\mathrm{pg} / \mathrm{mL}$ and were calculated according to a standard curve.

\section{Statistical analysis}

All assays were performed in triplicate in three different experiments. The results are expressed with statistical significance determined by analysis of variance followed by Student's t-test. A $p$-value $\leq 0.05$ was considered significant. The data were analyzed using GraphPad Prism 7.

\section{Results}

Anti-amastigote activity promoted by the AgNP-PVP-MA nanocomposite

Following treatment with AgNP-PVP-MA nanocomposite in the concentration described or amphotericin $\mathrm{B}$ $(0.5 \mu \mathrm{g} / \mathrm{mL})$, as a reference drug, after $24 \mathrm{~h}$ of incubation, infection levels were similarly reduced with both the reference drug (275 mean value of infection) and the nanocomposite (284.33 mean value of infection) compared to those in the untreated control group (Fig. 1A), with 576 mean value of infection, demonstrating the anti-leishmanial potential of the nanocomposite. Additionally, a descriptive table were presented with the mean values of the infection percentage, number of amastigotes per macrophage and infection index (Fig. 1A). A significant reduction in the amastigote number in the group treated with AgNP-PVP-MA nanocomposite (Fig. $1 \mathrm{C}$ - white arrow) compared to those in the untreated control group (Fig. 1B) and the amphotericin B-treated group (Fig. 1D - white arrow) was determined by fluorescence microscopy.

\section{Morphological alterations in promastigotes and amastigotes promoted by the AgNP-PVP-MA nanocomposite}

First, using SEM, several alterations in promastigote morphology were observed, including changes in body shape, wrinkled cell membrane, rounded body and shortened flagellum (Fig. 2B, C and D), compared with that of promastigotes in the untreated group (Fig. 2A). In addition, were observed small vesicles (SVs) in the body and flagellum (Fig. 2D-F). The group treated with amphotericin B (Fig. 2G) presented a body morphology completely altered by the drug effects, with extensive membrane destruction, despite it presented an elongated flagellum.

After evaluating the surface structure of the parasite by SEM, ultrastructural changes in the organelles of the promastigote and amastigote forms of Leishmania amazonensis were determined after AgNP-PVP-MA nanocomposite treatment by TEM. Promastigotes without 

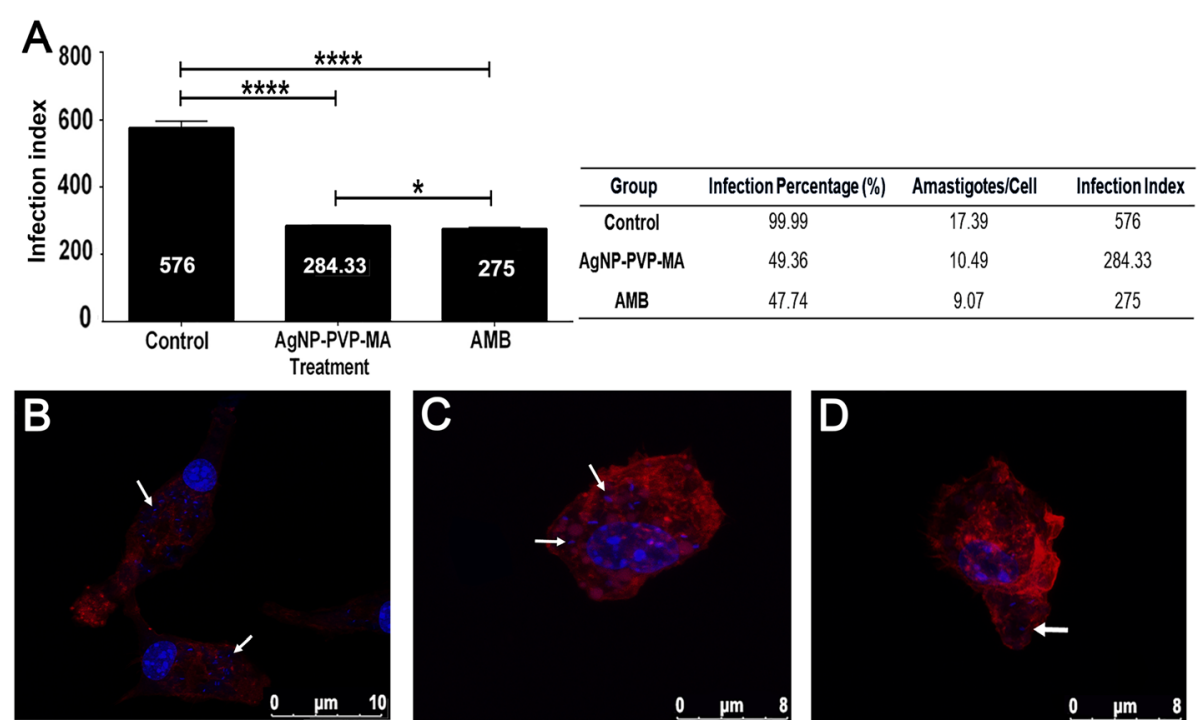

Fig. 1 Infection index of macrophages infected with Leishmania amazonensis. Graph showing the levels of infection index obtained after study and descriptive table of mean values for infection percentage, number of amastigotes per macrophage and infection index (A). Fluorescence labeling of infected macrophages, untreated (negative control); after $24 \mathrm{~h}$ of incubation (B). Fluorescence labeling of infected macrophages treated with AgNP-PVP-MA nanocomposite (AgNP to $1 \%, 0.1 \mathrm{~g}$ of PVP and $50 \mu \mathrm{g} / \mathrm{mL}$ of MA) incubated for $24 \mathrm{~h}$. (C). Fluorescence labeling of infected macrophages treated with AMB (positive control) at a concentration of $0.5 \mu \mathrm{g} / \mathrm{mL}$ incubated for $24 \mathrm{~h}$. Actin filaments - phalloidin in red (1:200) and DAPI in blue (1:100) was used (D). White arrow: amastigote forms. Control group: macrophages infected but untreated. AgNP-PVP-MA group: macrophages infected and treated with the nanocomposite. AMB group: macrophages infected and treated with amphotericin B. Analysis of variance, Student's t-test: ${ }^{*} p \leq 0.05 ;{ }^{* * *} p \leq 0.0001$

treatment had typical organelle morphology (Fig. 3A); however, when exposed to the nanocomposite, the parasite displayed vesicles containing electron-dense material in the nuclear membranes (Fig. 3B - arrows), showing the beginning of the apoptotic process, with chromatin condensation in the nuclear periphery (Fig. 3D - asterisks). In addition, a myelin-like structure was observed in mitochondria (Fig. 3C - arrowhead) and the Golgi complex (Fig. 3E - arrowhead), suggesting the accumulation of the nanocomposites in vesicles (Fig. $3 \mathrm{C}$ - asterisks, and, 3E - crosses). Plasma membrane rupture was also observed (Fig. 3D - arrowhead), in addition to the presence of morphological alterations in the flagellar membrane (Fig. $3 \mathrm{~F}$ - arrowhead).

The preservation of organelles and typical morphology were observed in the infected and untreated macrophages, as in the negative control (Fig. 4A and B). The presence of AgNP-PVP-MA nanocomposite was visualized in different areas in Leishmania amazonensis infected and treated macrophages (Fig. 4C - inset). The presence of the nanocomposite was observed in some regions: parasitophorous vacuole (Fig. 4E - asterisks), inside the parasite vesicles (Fig. 4D), and in proximity to the subpellicular microtubule (Fig. 4D F), flagellar pocket and multivesicular bodies (Fig. 4F - asterisk). The positive control group macrophages infected and treated with $A M B$ showed the absence of amastigote forms
(Fig. 4G - inset) and several incidences of cellular debris inside the parasitophorous vacuoles (Fig. $4 \mathrm{H}$ - asterisks).

\section{ROS and NO levels in infected macrophages treated with AgNP-PVP-MA nanocomposite}

After the treatment of infected macrophages, differences in NO production and ROS were observed between experimental groups and the untreated control group (infected macrophages without treatment). In the ROS measurement, the highest levels were observed in the group treated with the AgNP-PVP-MA nanocomposite, with significant differences compared to untreated control group (Fig. 5A). Regarding indirect NO detection, no significant differences were found between the untreated control group and the group treated with the nanocomposite, but there were significant differences in relation to the control group with the amphotericin $\mathrm{B}$ drug (Fig. 5B).

\section{Production of cytokines and chemokines in infected} macrophages treated with AgNP-PVP-MA nanocomposite From the infected and treated macrophage culture supernatants, the production levels of cytokines and chemokine profiles were determined. First, IL-4, and TNF- $\alpha$ levels increased after treatment compared to those in the control group (untreated cells). IL-4 showed 

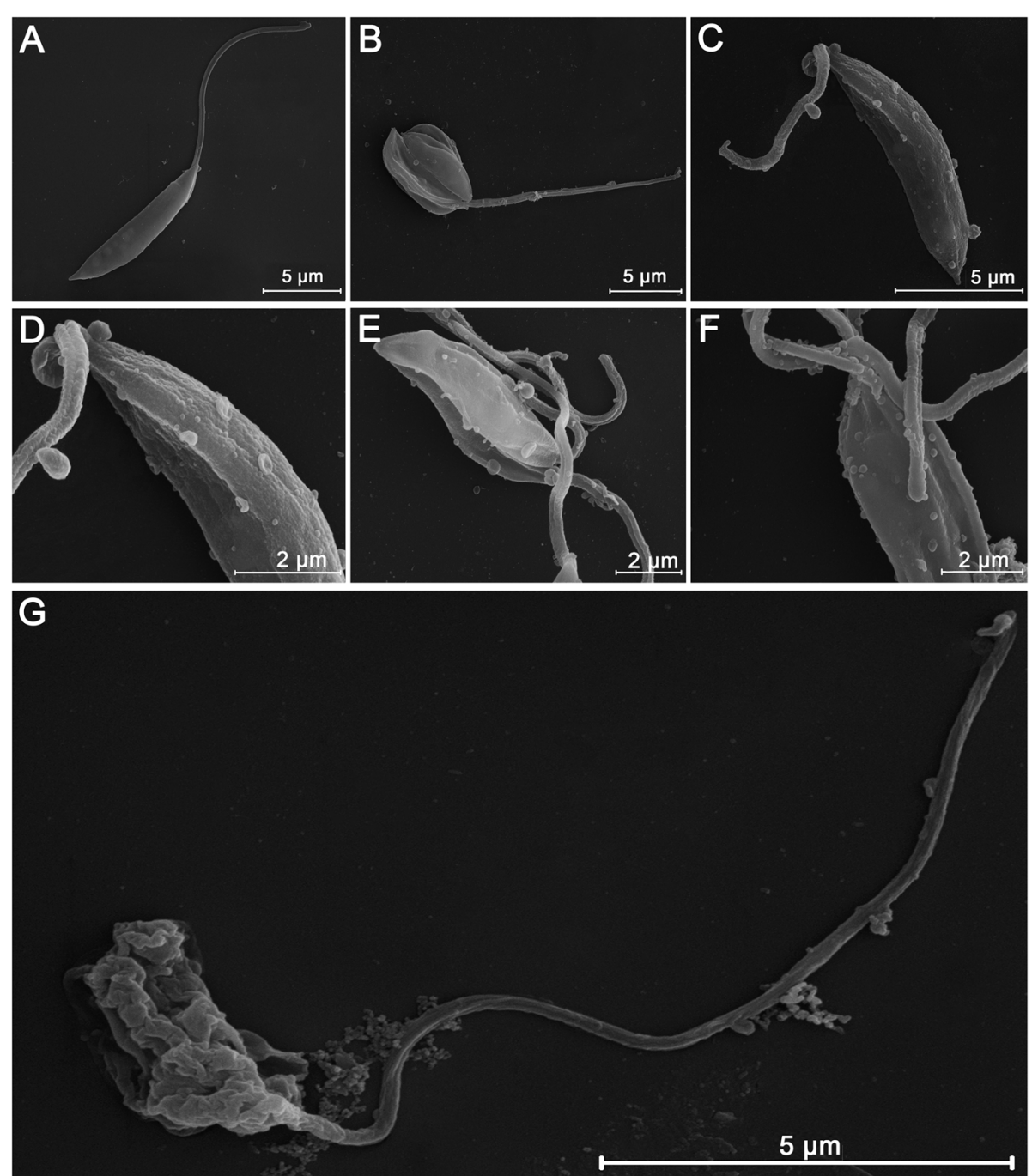

Fig. 2 Scanning electron micrographs of Leishmania amazonensis promastigotes treated with the AgNP-PVP-MA nanocomposite (AgNP to $1 \%$, $0.1 \mathrm{~g}$ of PVP and $50 \mathrm{\mu g} / \mathrm{mL}$ of MA) for $96 \mathrm{~h}$. A promastigote without treatment had preserved typical elongated morphology with externalized flagellum in excellent conditions (A). A promastigote with the presence of changes in body size (rounded body), compared with promastigotes in the untreated group, generated by the action of the AgNP-PVP-MA nanocomposite (B). A promastigote treated with AgNP-PVP-MA and presenting changes in body and the flagellum size, with rough type structure (C). Treated promastigote showing changes in the structure of the parasite, such as a wrinkled cell membrane (D). Promastigotes presenting alterations in the body shape with the presence of small vesicles (EVs) in the body $(\mathbf{E})$. The presence of small vesicles (EVs) in both the body and flagellum after treatment $(\mathbf{F})$. A promastigote altered by the effect of $\mathrm{AMB}$ (positive control) at a concentration of $0.5 \mu \mathrm{g} / \mathrm{mL}$, with extensive membrane destruction (G)

substantial production in the groups treated with AgNPPVP-MA (approximately 3-fold increased) or AMB (approximately 5 -fold increased) compared to the IL-4 production in the control group (Fig. 6A). TNF- $\alpha$ (Fig. 6B) and the chemokine MIP-1 $\alpha$ (Fig. 6D) were produced in larger quantities in the nanocomposite-treated group than in both the untreated and AMB groups. Conversely, although IL-17 A was produced in all experimental groups, we observed reductions in IL-17 A levels in the treated groups [AgNP-PVP-MA and AMB] (Fig. 6C). The data of cytokines IL-2, IFN- $\gamma$, IL-6, IL-10, IL-1 $\beta$, and GM-CSF and the chemokines MCP-1 and RANTES were not shown because their level of detection was below the detection limit or were not detected during this assay.

\section{Discussion}

The conjugation of compounds, such as drugs and nanoparticles, is a nanotechnological option in the generation of new nanoformulations and/or drugs, with specific targeting $[6,7,17]$ due to increased therapeutic efficacy, inhibitory potential against pathogens and reduced toxicity in patients $[18,19]$. Recently, our group developed the 

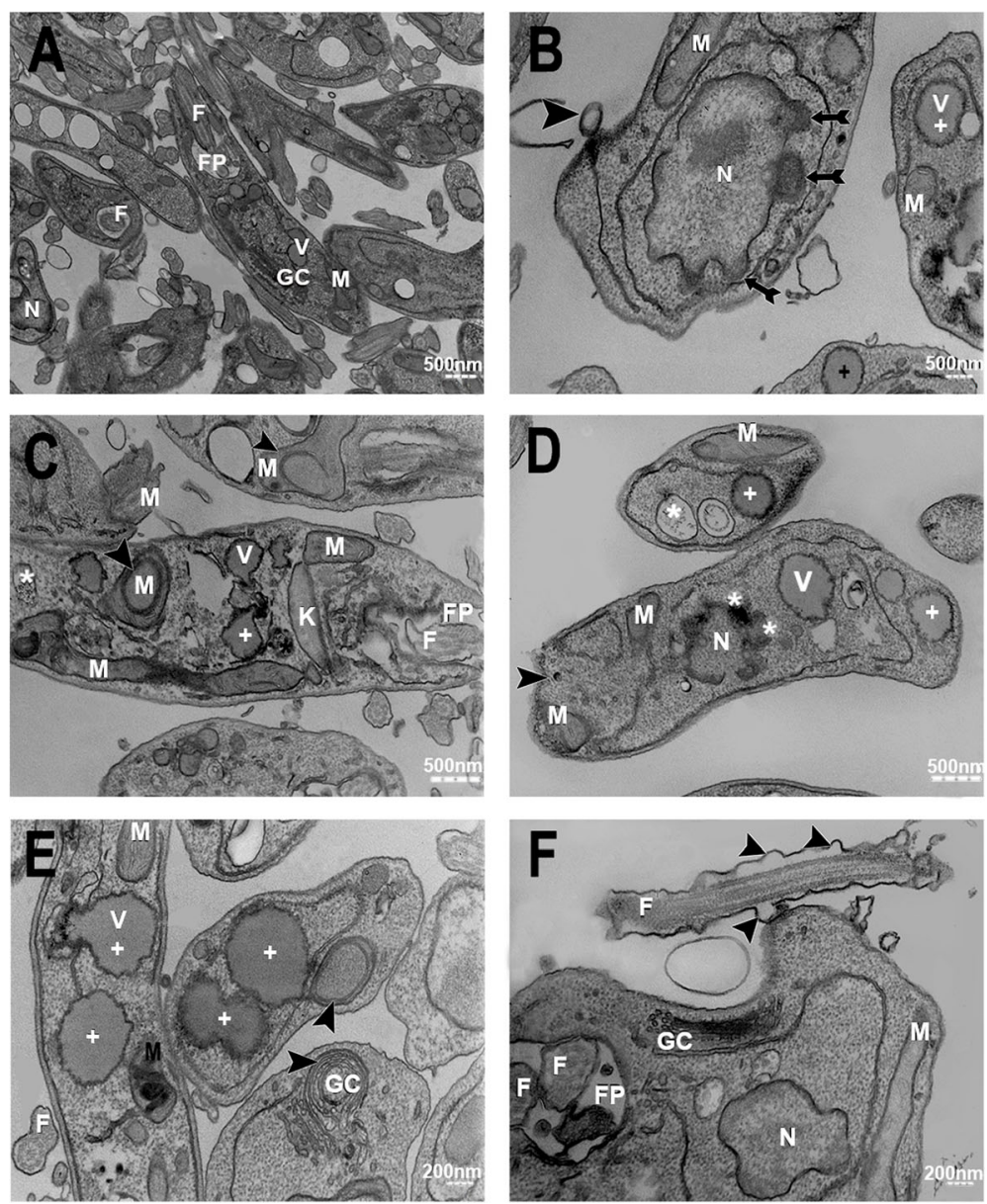

Fig. 3 Transmission electron micrographs of Leishmania amazonensis promastigotes after treatment with the AgNP-PVP-MA nanocomposite (AgNP to $1 \%, 0.1 \mathrm{~g}$ of PVP and $50 \mathrm{\mu g} / \mathrm{mL}$ of MA) for $96 \mathrm{~h}$. Promastigote forms without treatment (negative control), with typical morphology (A). Promastigotes displaying chromatin condensation in the nuclear periphery [arrows] (B). Changes in parasite vesicles [+], with possible accumulation of the nanocomposite [*], and the presence of myelin-like structures in mitochondria [ $](\mathbf{C})$. Plasma membrane rupture [ ] and the presence of vesicles containing electrondense material [asterisks] at the edges of the nucleus [N] (D). Altered vesicles [+] and the presence of myelin-like structures in the Golgi complex [ ] (E). Parasite flagellar membrane changes [ ] (F). N: Nucleus. M: Mitochondrion. F: Flagellum. FP. Flagellar pocket. GC: Golgi complex. V: Vesicles. K: Kinetoplast

new AgNP-PVP-MA nanocomposite as a potential alternative for leishmaniasis treatment [13]; however, the mechanism of action in relation to ultrastructural alterations in the parasite and the immune response of the infected host cell have not been determined. Thus, the purpose of this study was to complement the previous approach to determine the possible pathways and responses promoted by the nanocomposite.

Cell morphology is characterized by presenting unique alterations, dependent on the type of cell death induced in response to various stimuli [20], where through electron microscopy it is possible to elucidate the mechanism of action of drugs [21, 22]. Therefore, through SEM and TEM, ultrastructural alterations of the parasite were evaluated to establish the possible type of cell death (i.e., necrosis, apoptosis or autophagy). In the SEM analysis of promastigotes treated with the nanocomposite, a shortening of the flagellum was observed, as well as changes in body shape with rough type structure and rounded body, and the presence of small extracellular vesicles (EVs) in the parasite membrane, including the flagellar membrane, when compared to the untreated control group. Moreover, rupture of the plasma and flagellar membranes was observed, with the presence of EVs close to them, revealing another possible path of cell death, associated with the response of external stimuli, in different biological and pathological processes [23, 24]. In addition, EVs are usually present in all biological fluids and are considered possible biomarkers for infectious diseases [25-27], such as those caused by Toxoplasma gondii [28], Leishmania major [29], and Plasmodium yoelii [30]. However, the content of the EVs and their role in the pathogenesis 


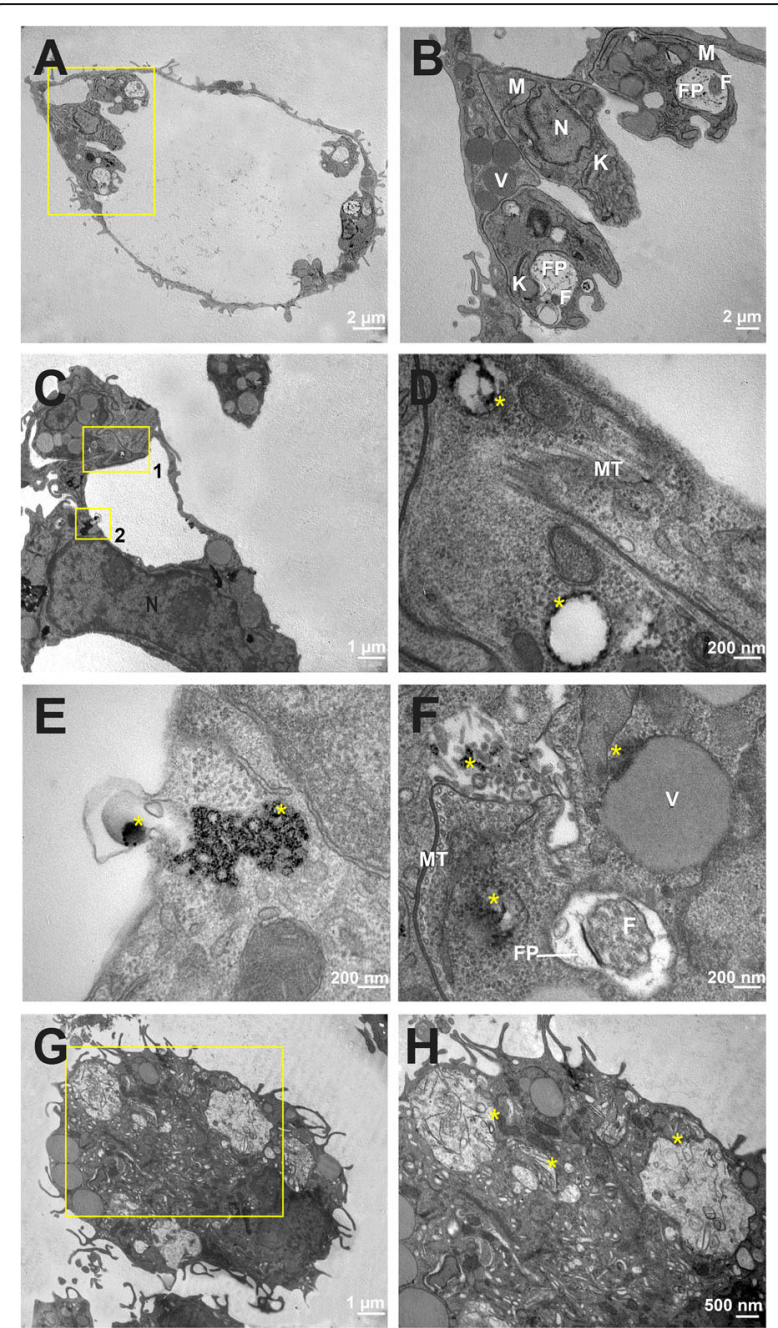

Fig. 4 Transmission electron micrographs of Leishmania amazonensis intracellular amastigotes after treatment with the AgNP-PVP-MA nanocomposite (AgNP to $1 \%, 0.1 \mathrm{~g}$ of PVP and $50 \mathrm{\mu g} / \mathrm{mL}$ of MA) for $24 \mathrm{~h}$. The image shows the parasitophorous vacuole of an infected macrophage in control group (A). Amplification of image (A), showing amastigotes with typical morphology (B). A macrophage infected and treated with AgNPPVP-MA, showing the presence of the nanocomposite in some regions [selected insets 1 and 2] (C). Amplification of inset 1 [image (C)]; presence of AgNP-PVP-MA (asterisks) in vesicles and close to the subpellicular microtubule was observed (D). Amplification of inset 2 [image (C)], with the presence of the nanocomposite (asterisks) inside the parasitophorous vacuole $(\mathbf{E})$. The nanocomposite (asterisks) near the flagellar pocket, multivesicular bodies and close to the subpellicular microtubule (F). A macrophage infected with Leishmania amazonensis and treated with the reference drug AMB (positive control) at a concentration of $0.5 \mu \mathrm{g} / \mathrm{mL}$, showing the absence of amastigotes [inset] (G). Amplification of the inset [image $(\mathrm{G})$ ], showing the presence of cellular debris inside the parasitophorous vacuole [asterisks] (H). $\mathbf{N}$ : Nucleus. $\mathbf{M}$ : Mitochondrion. F: Flagellum. FP: Flagellar pocket. MT: Subpellicular microtubule and immunological evasion are not yet well defined for the pathogenic species [31]. It is known that the secretion of EVs is associated with the transmission of stress signals [26], affecting the motility, regulation, and growth of the parasite [32], with strong proinflammatory properties [33] stimulated by the accumulation of $\mathrm{Ca}^{+}$in the cytoplasm [34,35]. We believe that the nanocomposite could act in this way of $\mathrm{Ca}^{+}$ metabolism to release the EVs; however, further assays are necessary to prove this hypothesis.

Another structural alteration observed was the induction of vesicles containing electron-dense material in the periphery of the nucleus, similar to those observed in the beginning of the apoptotic process, with chromatin condensation. The findings observed in the present study, such as nucleus alterations, rupture of the cell membrane and damage in mitochondria, were observed in the same species of parasites treated with different nanoparticles and amiodarone drugs [36, 37].

A myelin-like structure was observed in the treated groups in both the mitochondria and Golgi complex of parasites, essential organelles involved in the energy metabolism, oxidative phosphorylation, cell secretion and the distribution of macromolecules necessary for parasite survival. The myelin-like structure and the alterations in the ROS levels are associated with the autophagy process [38-40], and in our study, the nanocomposite seems to alter this pathway of death. The AgNP has a preference for some organelles such as mitochondria and nucleus, generating a potential collapse of the mitochondrial membrane when interacting with membrane proteins $[41,42]$, inducing cytotoxicity through numerous mechanisms, including oxidative stress [43], favoring the production of ROS, and the release of $\mathrm{Ag}^{+}$ions by dissolving AgNP. This behavior was observed [36, 44] when evaluating the Leishmania amazonensis parasite with silver nanoparticles, with observations of apoptosis-like events, a reduced percentage of infected macrophages, ROS production, loss of mitochondrial integrity and damage to the promastigote and amastigote forms of the membrane. The production of ROS in our study was not high when compared to the stimulus generated by the individual AgNP, possibly due to the types of interactions present in the nanocomposite and the presence of other compounds. However, oxidative stress is an important mechanism that is associated with cytotoxicity, and the AgNP present in our nanocomposite seems to favor the production of ROS in a controlled manner, as demonstrated by [36, 43] and [45], culminating in an intracellular parasite load reduction. Therefore, knowledge of how ROS influence the activation of the cell death program is important for revealing mechanisms that can be used for therapeutic intervention in major human diseases [39]. In general, 


\section{A}

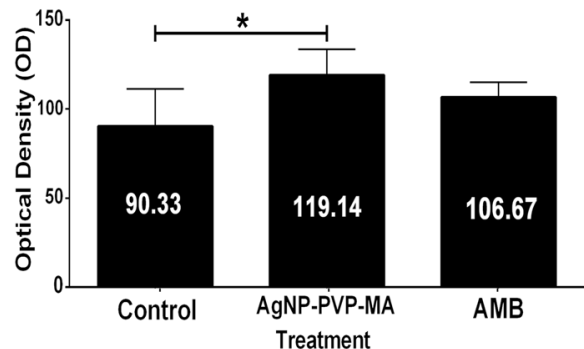

B

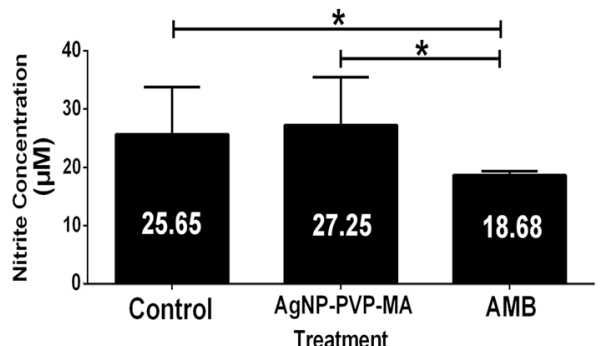

Fig. 5 Determination of reactive oxygen species levels and nitrite production after treatment with AgNP-PVP-MA nanocomposite (AgNP to $1 \%$, $0.1 \mathrm{~g}$ of PVP and $50 \mathrm{\mu g} / \mathrm{mL}$ of MA). Generation of ROS in macrophages infected with Leishmania amazonensis and treated with nanocomposite for $24 \mathrm{~h}(\mathbf{A})$. Levels of nitrite production in macrophages infected with Leishmania amazonensis and treated with nanocomposite for $24 \mathrm{~h}$ (B). Control group: macrophages infected and untreated. AgNP-PVP-MA group: macrophages infected and treated with the nanocomposite. AMB group: macrophages infected and treated with amphotericin B at a concentration of $0.5 \mu \mathrm{g} / \mathrm{mL}$. The results were expressed as mean \pm standard deviation of triplicate sample $(n=3)$ in three different experiments with analysis of variance, Student's t-test; ${ }^{*} p \leq 0.05$

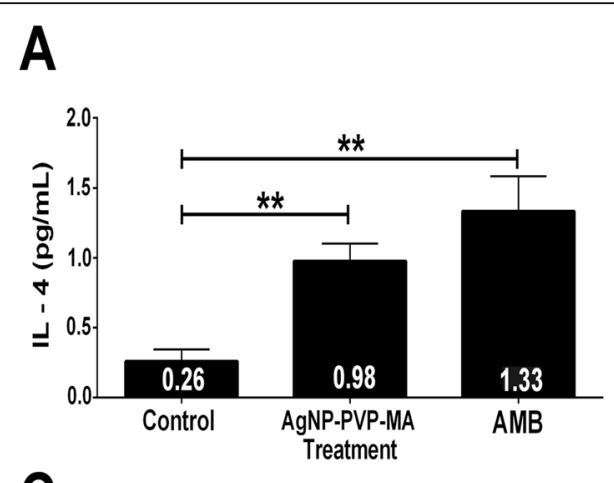

B
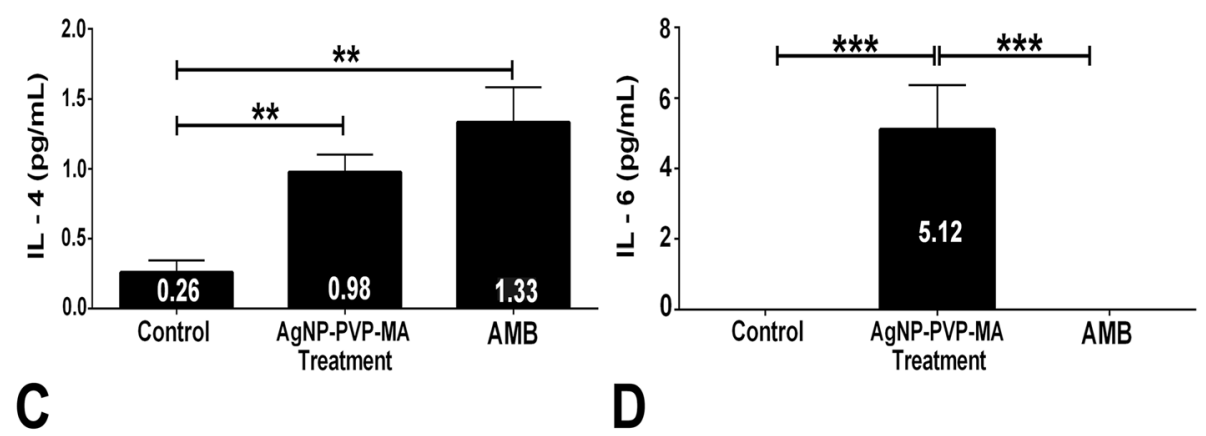

D
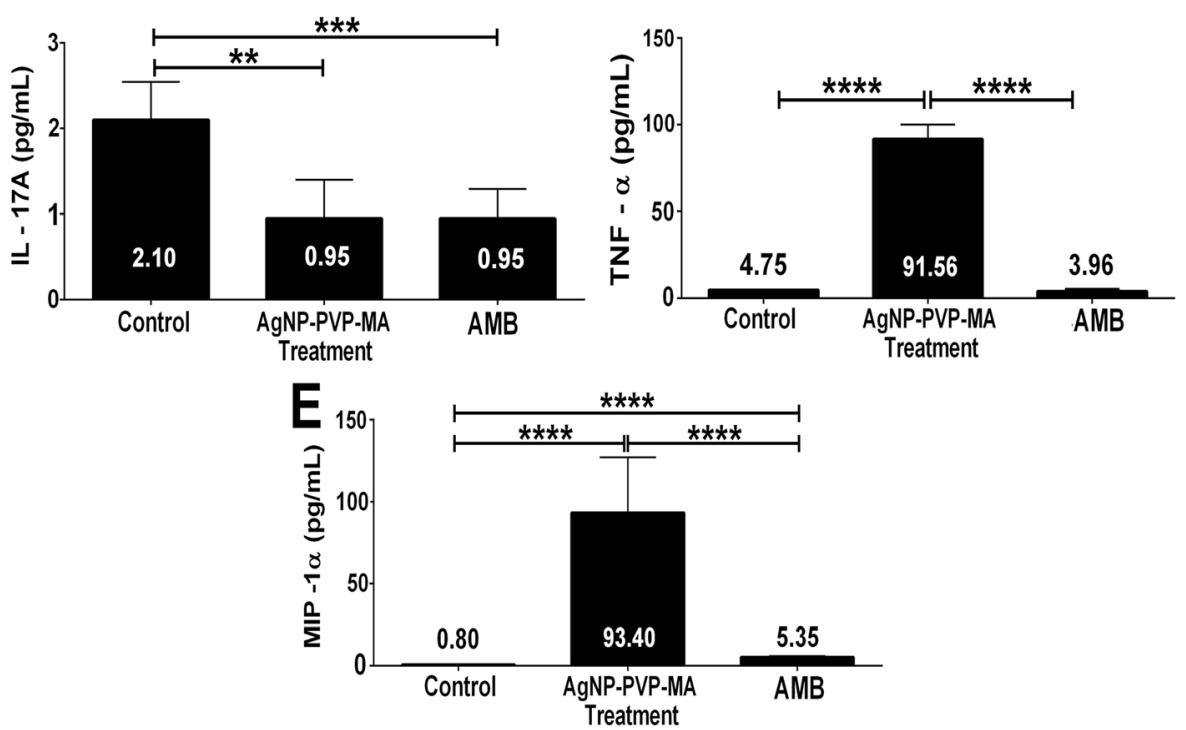

Fig. 6 Cytokine and chemokine levels after treatment with AgNP-PVP-MA nanocomposite (AgNP to 1\%, $0.1 \mathrm{~g}$ of PVP and $50 \mu \mathrm{gg} / \mathrm{mL}$ of MA) for $24 \mathrm{~h}$. Levels of interleukin 4 [IL-4] (A). Levels of tumor necrosis factor alpha [TNF-a] (B). Levels of interleukin 17 A [IL-17 A] (C). Levels of macrophage inflammatory protein-1 alpha [MIP-1a] (D). Control group: macrophages infected and untreated. AgNP-PVP-MA group: macrophages infected and treated with the nanocomposite. AMB group: macrophages infected and treated with amphotericin B at a concentration of $0.5 \mu \mathrm{g} /$ $\mathrm{mL}$. The results were expressed as mean \pm standard deviation of triplicate sample $(n=3)$ in three different experiments with analysis of variance, Student's t-test; ${ }^{*} p \leq 0.05 ;{ }^{* *} p \leq 0.005 ;{ }^{* * *} p \leq 0.0005 ;{ }^{* * *} p \leq 0.0001$ 
AgNPs are expected to induce toxicity through ROS induction, which is dependent on the nanoparticle type, chemistry and structure [46]. Thus, in our study, we observed that this mechanism is selective, as we could observe the presence of nanocomposites inside of the parasite and inside the parasitophorous vacuoles, showing that the delivery system works well, promoting a direct activity in intracellular amastigotes, increasing the ROS production of infected macrophages with reduction in the parasite number and without affecting the morphology of the host cell. These findings allow an understanding of how the cellular uptake of nanocomposite works inside the host cell and/or parasite, as those mechanisms are detected using several comprehensive technological tools, such as electron microscopy, helping to elucidate the pathways involved in the nanoformulation carrier and possible organelle targets [47].

Another important point determined in this study was the cytokine and chemokine production after the expose of Leishmania-infected cells to the nanocomposite. Successful immunity to Leishmania depends on the recruitment of appropriate immune effector cells: macrophages, NK cells, $\mathrm{CD} 4^{+}$and $\mathrm{CD}^{+}$cells, and Th1, Th2, Treg and Th17 cell differentiation [48], where anti-inflammatory and pro-inflammatory cytokines and chemokines play relevant roles in the regulation of cell differentiation, recruiting resident and migratory cells involved in the resistance and susceptibility to and the immunopathogenesis of Leishmania infection [49, 50]. Studies have reported that the resistance to leishmaniasis infection is related to a Th1 response, with the production of mainly pro-inflammatory cytokines, such as IL-12, which is indispensable in the production of IFN- $\gamma$ (not detected in our study), and, synergistically with TNF- $\alpha$, activates inducible nitric oxide synthase (iNOS or NOS2) to produce nitric oxide (NO), an important molecule for the reduction of intracellular parasites $[48,51]$. The cytokines IL-1 and IL-2 (not detected in our study) are responsible for the activation of macrophages and neutrophils as well as the production of ROS [49, 52, 53]. In contrast, some parasites, such as Leishmania amazonensis, guarantee their survival by modulating the host immune system, promoting a host susceptibility associated with a Th2 response [54], with the production of IL-4, IL-5, IL-10 and IL-13, responsible for parasite replication and persistence $[51,55,56]$.

In our study, only the cytokines IL-4, IL-17 A, and TNF- $\alpha$ and the chemokine MIP- $1 \alpha$ were detected. It has been reported that TNF- $\alpha$ and IL- 6 are important in the formation of the apoptotic process [51, 57], which seemed to occur in our study once suggestive alterations in the morphology of the parasite were observed, as discussed above. Additionally, studies have reported that AgNP and AuNP alone increase the secretion of pro-inflammatory cytokines such as IL-1ß, IL-2, IL-6, TNF- $\alpha$ and prostaglandin E2 (PGE-2), which are involved in parasite elimination mechanisms [58, 59], and the MA are able to induce the production of pro-inflammatory cytokines, which increases the phagocytic capacity of monocytes, macrophages and neutrophils $[60,61]$.

The presence of AgNP and MA in our nanocomposite seems to be related to the higher production of the proinflammatory cytokine TNF- $\alpha$ (compared with control groups) and chemokine MIP-1- $\alpha$, seems to induce the inflammatory process, usually observed in the early stages of infection and could be related with the reduction of the parasite load through the production of ROS which is also an inflammatory marker. Besides, the chemokine MIP-1 $\alpha$ (CCL3) is known to induce IL-1, IL-6, and TNF- $\alpha$ production with chemotactic and proinflammatory effects and acts as homeostasis promoter culminating in a Th1 response in the presence of receptors CCL3 and CCR5, fundamental in the control of leishmaniasis [50, 51].

Thus, the Th1 response is fundamental in the control of leishmaniasis and is responsible for the activation of macrophages in skin lesions, along with CCL2, reducing the parasitic load [50, 51, 62]. Moreover, the nanocomposite seems to induce this kind of response in Leishmania-infected cells. The other chemokines evaluated, GM-CSF and MCP-1(CCL2), which have important roles in early immunity against cutaneous leishmaniasis [63], were not detected in our study, possibly due to the absence of some cytokines and chemokines associated with their expression, which were not promoted by the nanocomposite, at least in the first $24 \mathrm{~h}$, demonstrating other ways to fight the parasite.

Conversely, IL-17 A, responsible for activating signaling pathways that lead to chemokine induction with TNF- $\alpha$ and IL-1, inducing the production of IL- 6 , GMCSF, IL- $1 \beta$, TGF- $\beta$, IL-8 and MCP-1 [57], but was little detected in our study, indicating the activation of other routes different of Th17 responses.

It is well known that macrophages are one of the first cell types to act as a defense against Leishmania parasites during the infectious process, and in addition to ROS, they produce $\mathrm{NO}$ and cytokines and chemokines as important mechanisms to control leishmaniasis disease [49]. This control mechanism depends on the species of Leishmania involved in clinical manifestations, the different immunological pathways in which pro- and anti-inflammatory cytokines play different roles in resistance or susceptibility, and the immunopathogenesis of the host [48, 64]. For Leishmania amazonensis, one of the main etiological agents of leishmaniasis in the Amazonian region [64], a Th2 response against infection is 
generally developed, confirmed by the presence of high levels of IL-4 and IL-10, and accompanied by the production of IgG1 antibody isotypes [54, 56]. However, some strains of Leishmania amazonensis guarantee their survival by modulating the host immune system, inducing immunosuppression and are able to reduce the inflammatory response, especially in the initial stages of infection process, which decreases the effectiveness of treatment [50, 54, 64]. Cytokines and chemokines have complex and important roles in the promotion and suppression of immune cells in the leishmaniasis infectious process. The IL- 4 is usually associated with a Th2 response, responsible for the replication and persistence of the Leishmania parasite. However, recently it was demonstrated the dual role of this cytokines, as antiLeishmania in the presence of MIF, GM-CSF, TNF- $\alpha$, IFN- $\gamma$, IL-2, IL-7, IL-15, and, pro-Leishmania in the presence of IL-10, TGF- $\beta$, IL-6, IL-13, MIF, IL-3; showing its diverse interventions in the infectious process of Leishmaniasis [65]. Despite in our study we observed higher production of this cytokines in the nanocomposite group compared with control group, the production was lower and was not able to suppress the TNF production.

In this way, we believe that the nanocomposite seems to partially reverse this inhibitory mechanism generated by the Leishmania amazonensis and, associated with the production of ROS and expression of Th1 cytokines and

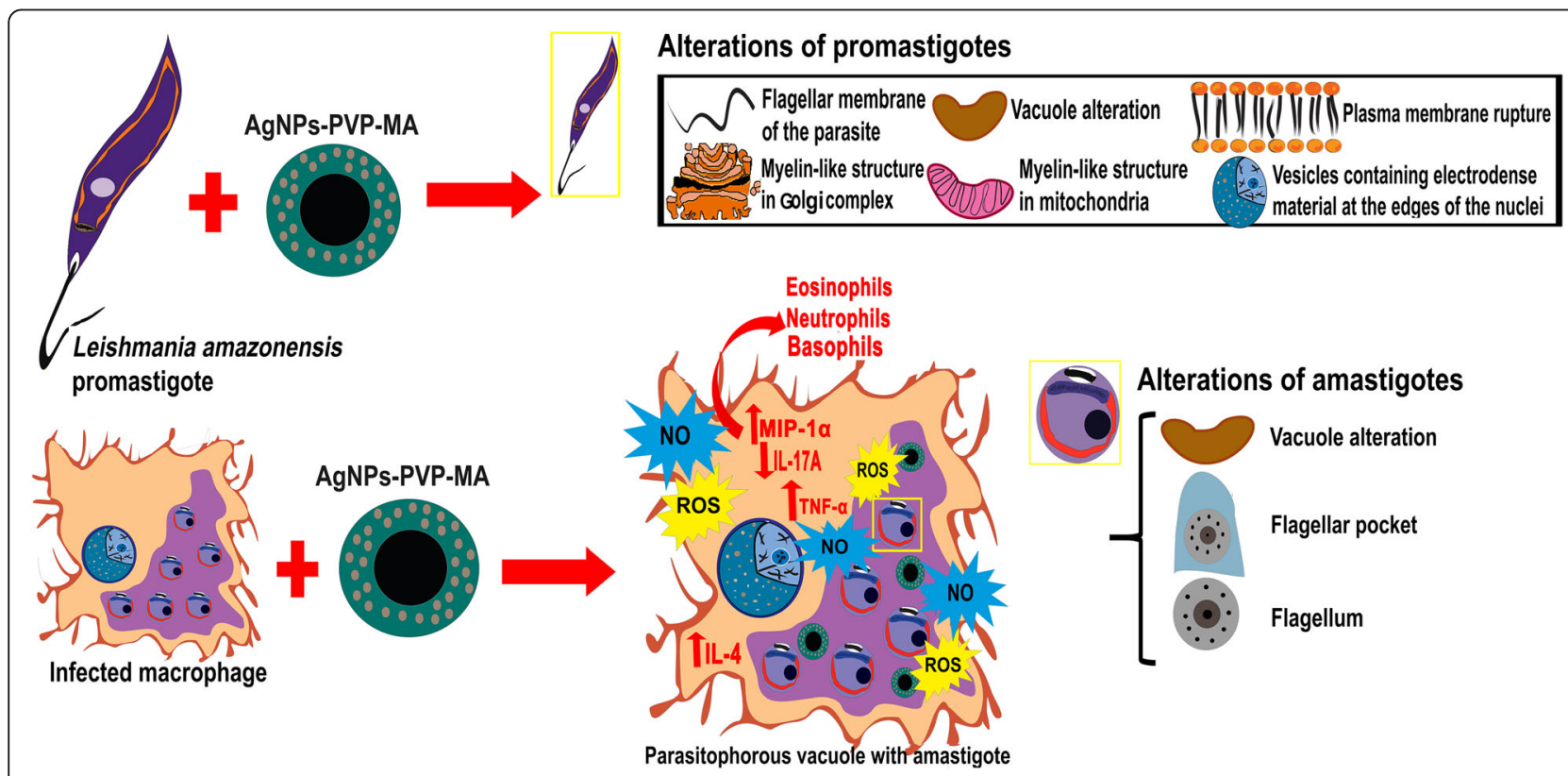

Fig. 7 Cell behavior after treatment with AgNP-PVP-MA nanocomposite. After infection of macrophages with Leishmania amazonensis and later treatment with the AgNP-PVP-MA, generated that, as mechanism of action promoted by nanocomposite, the pro-inflammatory and antiinflammatory cytokines TNF- $\mathrm{a}, \mathrm{IL}-4$, and IL-17 A and the chemokine MIP-1a were expressed, as the main mediators during infection of the parasite this study; being involved in different roles as resistance, susceptibility and immunopathogenesis, and being indispensable during infection control of parasite in the leishmaniasis. Resistance to leishmaniasis is related to the development at a Th1 response and its respective production of pro-inflammatory cytokines, like TNF- $a, \mathrm{IL}-6$, and, IL-17 A, which are responsible for activating macrophages and generating the death of parasites by the production of $\mathrm{NO}$ and ROS, responsible for the elimination of intracellular amastigotes. Our results may indicate that the ROS and NO pathways are not stimulated by the nanocomposite, since their expression was low in ROS and NO, which leads to a low activation and stress of macrophages in the presence of the nanocomposite, can being other pathways can being involved in the action mechanism these. On the other hand, less IL-4 and IL-17 A were produced and IL-17 was reduced in the presence of the nanocomposite. In addition, the chemokine MIP-1a produced in large quantities by macrophages in our study is characterized by chemotactic and pro-inflammatory effects and is crucial for immune responses toward infection and inflammation. Furthermore, neutrophils, eosinophils and basophils, are favored by the presence of TNF-a, responsible for pro-inflammatory functions as well as the death of parasites because of their cytotoxic function. They also induce the synthesis and release of other pro-inflammatory cytokines by macrophages. Parasite death was determined by the presence of ultrastructural changes in the two developmental forms of the Leishmania, which were highlighted in the promastigote form as a compromised nucleus, possible initiation of the apoptotic process and chromatin condensation in the nuclear periphery and the presence of a myelin-like structure in the mitochondrial and Golgi complex organelles. In the case of the amastigote form, the specificity of the AgNP-PVP-MA nanocomposite was predominant by ultrastructural alterations in the flagellum, vacuole and flagellar pocket, with presence of nanocomposite in vesicles and close to the subpellicular microtubule, showing promoted possibly an mechanism of action directed by specific parasite organelles of Leishmania and its potential as a new treatment alternative for cutaneous leishmaniasis disease with the stimulation of a Th1 response. ROS: reactive oxygen species. NO: nitric oxide. TNF-a: tumor necrosis factor alpha. IL-4: Interleukin 4. IL-6: Interleukin 6. IL-17 A: Interleukin 17 A. MIP-1a: macrophage inflammatory protein-1 alpha. iNOS2: inducible nitric oxide synthase 2. AgNP: silver nanoparticles 
chemokines, culminates in a reduction of intracellular amastigotes, as well as significant ultrastructural alteration, showing the selective action of this nanocomposite against the Leishmania parasite.

Thus, these findings were important for providing a better understanding of the possible mechanism of action of the AgNP-PVP-MA nanocomposite as a promising alternative option for the control of leishmaniasis. In this way, the next step for the application of the nanocomposite is the incorporation of it in a noninvasive vehicle that could be used as local dermal treatment for cutaneous leishmaniasis.

\section{Conclusions}

The important findings generated from the present study allowed to establish, for the first time, the effect of the AgNP-PVP-MA nanocomposite, in the parasite and infected host cell, reversing the inhibitory process of the immune response generated by the species of Leishmania amazonensis, stimulated a Th1 response and generated ultrastructural alterations in relevant organelles in the two forms of the parasite, activating an important cell death mechanism by the autophagy process, elucidated by electron microscopy (summarized in Fig. 7). In this way, the present study showed that AgNP-PVP-MA acts in the different evolutive forms of Leishmania amazonensis by a direct activity or indirect response through activation of macrophages response.

\begin{abstract}
Abbreviations
MA: Meglumine Antimoniate (also known Glucantime ${ }^{\circledast}$ ); AgNP: Silver Nanoparticles; PVP: Polyvinylpyrrolidone; NO: Nitric Oxide; NO-2: Nitrite; NaNO2: Sodium Nitrite; ROS: Reactive Oxygen Species; CBA: Cytometric Bead Array; AMB: Amphotericin B; N: Nucleus; M: Mitochondria; F: Flagellum; FP: Flagellar Pocket; GC: Golgi Complex; V: Vacuole; K: Kinetoplast; MT: Subpellicular Microtubules; MIP-1a: Macrophage Inflammatory Protein-1 Alpha; EVs: Extracellular Vesicles; iNOS2: Inducible Nitric Oxide Synthase 2. ACL: American Cutaneous Leishmaniasis; CONCEA: National Council for the Control of Animal Experimentation; CEUA: Commission on the Ethics of Animal Experiments; IPФ: Intraperitoneal Macrophages
\end{abstract}

\section{Acknowledgements \\ The authors are grateful to the Leishmaniasis Laboratory "Prof. Dr. Ralph Lainson" - Instituto Evandro Chagas (IEC), Pró-reitoria de Pesquisa da Universidade Federal do Pará (PROPESP-UFPA) and Fundação de Amparo e Desenvolvimento da Pesquisa (FADESP). We also thank the Structural Biology Laboratory (Federal University of Pará) for support and assistance during assay analysis.}

\begin{abstract}
Authors' contributions
A. P. C. G.: Project conceptualization, methodology, performed the assays, analysis, wrote the original draft, prepared the figures; J. A. P. D. J.: microscopy analysis; R. T. S. S. B.: performed the assays and made results analysis, prepared the figures; A. P. D. R.: Project conceptualization, wrote, reviewed and edited the last version of manuscript, supervised the project execution. All authors approved the last version of the manuscript.
\end{abstract}

\section{Funding}

The authors acknowledge the financial support from the Institute Evandro Chagas (IEC), Department of Health Surveillance, Ministry of Health:
Laboratory of Electron Microscopy and Laboratory of Superficial and Systemic Mycoses. We thank Conselho Nacional de Desenvolvimento Científico e Tecnológico (CNPq), grant number: 424101/2016-5. This study was financed in part by the Coordenação de Aperfeiçoamento de Pessoal de Nível Superior - Brasil (CAPES) - finance code 001.

\section{Availability of data and materials}

All data generated or analysed during this study are included in this published article.

\section{Declarations}

Ethics approval and consent to participate

This research was performed according to institutional animal ethics guidelines and Brazilian Animal Protection Law (Lei Arouca number 11.794/ 08) of the National Council for the Control of Animal Experimentation (CONCEA, Brazil). The protocol was approved by the Commission on the Ethics of Animal Experiments of the Evandro Chagas Institute (CEUA 14/ 2016).

\section{Consent for publication}

Not applicable.

\section{Competing interests}

The authors declare that they have no competing interests.

\section{Author details}

${ }^{1}$ Evandro Chagas Institute, Secretary of Health Surveillance, Laboratory of Electron Microscopy, Ministry of Health, Av. Almirante Barroso, 492, Marco, Pará 66090-000 Belém, Brazil. ²Postgraduate Program in Biology of Infectious and Parasitic Agents, Federal University of Pará, R. Augusto Corrêa, 01 Guamá, Pará CEP: 66075-110 Belém, Brazil.

Received: 20 January 2021 Accepted: 10 June 2021

Published online: 12 July 2021

\section{References}

1. Organización Panamericana de la Salud (OPAS). Manual de procedimientos para la vigilancia y control de las leishmaniasis en las Américas. Washington, D.C.: OPS; 2019

2. World Health Organization (WHO). Leishmaniasis. Guide of the WHO/PAHO Expert Committee on the Control of Leishmaniases. Epidemiological Report of the Americas № 7. Washington, D.C: World Health Organization; 2019. https://iris.paho.org/bitstream/handle/10665.2/50505/Leishreport2019_eng. pdf?ua $=1$

3. Palumbo E. Treatment strategies for mucocutaneous leishmaniasis. J Global Infect Dis. 2010;2(2): https://doi.org/10.4103/0974-777x.62879.

4. Mcgwire BS, Satoskar AR, Leishmaniasis. Clinical syndromes and treatment. QJM. 2014;107(1):7-14.

5. Anversa LS, Tiburcio MG, Richini-Pereira VB, Ramirez LE. Human leishmaniasis in Brazil: a general review. Rev Assoc Med Bras. 2018;64(3): 281-9.

6. de Souza A, Marins DSS, Mathias SL, Monteiro LM, Yukuyama MN, Scarim CB, Löbenberg R, Bou-Chacra NA. Promising nanotherapy in treating leishmaniasis. Int J Pharm. 2018:547(1-2):421-31.

7. Akbari M, Oryan A, Hatam G. Application of nanotechnology in treatment of leishmaniasis: A Review. Acta Tropica. 2017; 172:86-90.

8. Safari J, Zamegar Z. Advanced drug delivery systems: Nanotechnology of health design A review. J Saudi Chem Soc. 2014;18(2):85-99.

9. Want MY, Yadav P, Afrin F. Nanomedicines for Therapy of Visceral Leishmaniasis. J Nanosci Nanotechnol. 2016;16(3):2143-51.

10. Kalat SAM, Khamesipour A, Bavarsad N, Fallah M, Khashayarmanesh Z, Feizi E, Neghabi K, Abbasi A, Jaafari MR. Use of topical liposomes containing meglumine antimoniate (Glucantime) for the treatment of L-major lesion in BALB/c mice. Exp Parasitol. 2014;143:5-10.

11. Borborema SET, Osso JA, de Andrade HF, do Nascimento N. Antimonial drugs entrapped into phosphatidylserine liposomes: physicochemical evaluation and antileishmanial activity. Rev Soc Bras Med Trop. 2016;49(2): 196-203.

12. Mahmoudvand H, Shakibaie M, Tavakoli R, Jahanbakhsh S, Sharifi I. In vitro study of leishmanicidal activity of biogenic selenium nanoparticles against 
Iranian isolate of sensitive and glucantime- resistant Leishmania tropica. Iran J Parasitol. 2014;9(4):452-60.

13. Gélvez APC, Farias LHS, Pereira VS, da Silva ICM, Costa AC, Dias CGBT, Costa RMR, da Silva SHM, Rodrigues APD. Biosynthesis, characterization and leishmanicidal activity of a biocomposite containing AgNPs-PVP-glucantime. Nanomedicine. 2018;13(4):373-90. https://doi.org/10.2217/nnm-2017-0285.

14. Rodrigues APD, Farias LHS, Carvalho ASC, Santos AS, Do Nascimento JLM, Silva EO. A novel function for kojic acid, a secondary metabolite from Aspergillus fungi, as antileishmanial agent. PLoS ONE. 2014;9 (3): https://doi org/10.1371/journal.pone.0091259.

15. Green SJ, Meltzer MS, Hibbs JB, Nacy CA. Activated macrophages destroy intracellular Leishmania major amastigotes by an L-arginine-dependent killing mechanism. J Immunol. 1990;144(1):278-83.

16. Ding $A H$, Nathan CFS. Release of reactive nitrogen intermediates and reactive oxygen intermediates from mouse peritoneal macrophages: Comparison of activating cytokines and evidence for independent production. J. Immunol. 1988; 141: 2407-2412.

17. Lopera Sepúlveda A, Arenas A, Patiño I, de Almeida L, Fontana C, Garcia C, Silva M. Efficacy of photodynamic therapy using $\mathrm{TiO} 2$ nanoparticles doped with $\mathrm{Zn}$ and hypericin in the treatment of cutaneous Leishmaniasis caused by Leishmania amazonensis. Photodiagn Photodyn Ther. 2020;30: https://doi. org/10.1016/j.pdpdt.2020.101676.

18. Ahmad A, Wei Y, Syed F, Khan S, Khan GM, Tahir K, Khan AU, Raza M, Khan FU, Yuan Q. Isatis tinctoria mediated synthesis of amphotericin B-bound silver nanoparticles with enhanced photoinduced antileishmanial activity: A novel green approach. J Photochem Photobiol B Biol. 2016;161:17-24.

19. Kalangi SK, Dayakar A, Gangappa D, Sathyavathi R, Maurya RS, Narayana Rao D. Biocompatible silver nanoparticles reduced from Anethum graveolens leaf extract augments the antileishmanial efficacy of miltefosine. Exp Parasitol. 2016;170:184-92.

20. Majno G, Joris I. Apoptosis, oncosis, and necrosis. An overview of cell death. Am J Pathol. 1995;146(1):3-15.

21. Condello M, Caraglia M, Castellano M, Arancia G, Meschini S. Structural and functional alterations of cellular components as revealed by electron microscopy. Microscopy Res Techn. 2013;76(10):1057-69.

22. Adade CM, Souto-padrón T. Contributions of Ultrastructural Studies to the Cell Biology of Trypanosomatids: Targets for Anti-Parasitic Drugs. Open Parasitol J. 2010:4:178-87.

23. Marcilla A, Martin-Jaular L, Trelis M, de Menezes-Neto A, Osuna A, Bernal D, Fernandez-Becerra C, Almeida IC, del Portillo HA. Extracellular vesicles in parasitic diseases. J Extracell Vesicl. 2014;3(1): https://doi.org/10.3402/jev.v3.2 5040.

24. Marti M, Johnson PJ. Emerging roles for extracellular vesicles in parasitic infections. Curr Opin Microbiol. 2016;32:66-70.

25. Properzi F, Logozzi M, Fais S. Exosomes: the future of biomarkers in medicine. Biomarkers Med. 2013;7(5):769-78.

26. Schorey JS, Cheng Y, Singh PP, Smith VL. Exosomes and other extracellular vesicles in host-pathogen interactions. EMBO Rep. 2015;16(1):24-43.

27. Schorey Jeffrey S, Harding CV. Extracellular vesicles and infectious diseases: new complexity to an old story. J Clin Investig. 2016;126(4):1181-9.

28. Aline F, Bout D, Amigorena S, Dimier-poisson I, Roingeard P. Toxoplasma gondii Exosomes Induce a Protective Immune Response against T. gondii Infection Toxoplasma gondii Antigen-Pulsed-Dendritic Cell-Derived Exosomes Induce a Protective Immune Response against T. gondii Infection. Infect Immun. 2004;72(7):4127-37.

29. Schnitzer JK, Berzel S, Fajardo-Moser M, Remer KA, Moll H. Fragments of antigen-loaded dendritic cells (DC) and DC-derived exosomes induce protective immunity against Leishmania major. Vaccine. 2010;28(36):578593.

30. Martin-Jaular L, Nakayasu ES, Ferrer M, Almeida IC, del Portillo HA. Exosomes from Plasmodium yoelii-infected reticulocytes protect mice from lethal infections. PLoS ONE. 2011;6(10): https://doi.org/10.1371/journal.pone.002 6588.

31. Neves RFC, Fernandes ACS, Meyer-Fernandes JR, Souto-Padrón T. Trypanosoma cruzi-secreted vesicles have acid and alkaline phosphatase activities capable of increasing parasite adhesion and infection. Parasitol Res. 2014;113(8):2961-72.

32. Eliaz D, Kannan S, Shaked H, Arvatz G, Tkacz ID, Binder L, Waldman BenAsher H, Okalang U, Chikne V, Cohen-Chalamish S, Michaeli S. Exosome secretion affects social motility in Trypanosoma brucei. PLoS Pathogens. 2017;13(3): https://doi.org/10.1371/journal.ppat.1006245.
33. Hassani K, Shio MT, Martel C, Faubert D, Olivier M. Absence of metalloprotease GP63 alters the protein content of leishmania exosomes. PLoS ONE. 2014;9(4): https://doi.org/10.1371/journal.pone.0095007.

34. Sedgwick AE, D'Souza-Schorey $C$. The biology of extracellular microvesicles. Traffic. 2018; 19 (5): 319-327.

35. Théry C, Ostrowski M, Segura E. Membrane vesicles as conveyors of immune responses. Nat Rev Immunol. 2009;9(8):581-93.

36. Ovais M, Nadhman A, Khalíl A, Raza A, Khuda F, Sohaíl M, Zakiullah UI, Islam N, Sarwar H, Shahnaz G, Ahmad I, Saravanan M, Shinwari Z. Biosynthesized colloidal silver and gold nanoparticles as emerging leishmanicidal agents: an insight. Nanomedicine (Lond). 2017. https://doi.org/10.2217/nnm-20170233.

37. de Macedo-Silva ST, de Oliveira Silva TLA, Urbina JA, de Souza W, Rodrigues JCF. Antiproliferative, Ultrastructural, and Physiological Effects of Amiodarone on Promastigote and Amastigote Forms of Leishmania amazonensis. Mol Biol Int. 2011;876021: https://doi.org/10.4061/2011/876021.

38. Kondo Y, Kanzawa T, Sawaya R, Kondo S. The role of autophagy in cancer development and response to therapy. Nat Rev Cancer. 2005;5(9):726-34.

39. Ott M, Gogvadze V, Orrenius S, Zhivotovsky B. Mitochondria, oxidative stress and cell death. Apoptosis. 2007; 12 (5): 913-922.

40. Cola J, Rodrigues F, Souza W. Ultrastructural Alterations in Organelles of Parasitic Protozoa Induced by Different Classes of Metabolic Inhibitors. Curr Pharmaceutical Design. 2008;14:925-38.

41. Asharani PV, Mun GLK, Hande MP, Valiyaveettil S. Cytotoxicity and genotoxicity of silver nanoparticles in human cells. ACS Nano. 2009;3(2): 279-90.

42. Riaz Ahmed KB, Nagy AM, Brown RP, Zhang Q, Malghan SG, Goering PL. Silver nanoparticles: Significance of physicochemical properties and assay interference on the interpretation of in vitro cytotoxicity studies. Toxicol in Vitro. 2017:38:179-92.

43. Völker C, Oetken M, Oehlmann, J. The Biological Effects and Possible Modes of Action of Nanosilver. D.M. Whitacre (ed.). Reviews of Environmental Contamination and Toxicology. 2013;223:81-106.

44. Rodrigues Fanti J, Tomiotto-Pellissier F, Miranda-Sapla M, Depieri Cataneo A, Tardeli de Jesus Andrade C, Panis C, da Silva Rodrigues J, Fanini Wowk P, Kuczera D, Costa I, Vataru Nakamura C, Nakazato G, Durán N, Rogério Pavanelli W, Conchon-Costa I. Biogenic silver nanoparticles inducing Leishmania amazonensis promastigote and amastigote death in vitro. Acta Tropica. 2018;178:46-54.

45. Dayakar Alti M, Veeramohan Rao D, Narayana Rao Radheshyam Maurya, Suresh K, Kalangi. Gold-Silver Bimetallic Nanoparticles Reduced with Herbal Leaf Extracts Induce ROS-Mediated Death in Both Promastigote and Amastigote Stages of Leishmania donovani. ACS Omega. 2020;5(26):1623845.

46. Nel A, Xia T, Madler L, Li N. Toxic potential of materials at the nanolevel. Science. 2006;311:622-7.

47. Shahed Behzadi Vahid, Serpooshan Wei, Tao Majd A, Hamaly, Mahmoud Y, Alkawareek Erik C, Dreaden Dennis, Brown, Alaaldin M, Alkilany, Omid C, Farokhzad, Morteza Mahmoudi. Cellular uptake of nanoparticles: journey inside the cell. Chem Soc Rev. 2017. https://doi.org/10.1039/c6cs00636a.

48. Maspi N, Abdoli A, Ghaffarifar F. Pro- and anti-inflammatory cytokines in cutaneous leishmaniasis: a review. Pathog Global Health. 2016;110(6):247-60.

49. Conceição-Silva F, Morgado F. Leishmania Spp-Host Interaction: there Is Always an Onset, but Is There an End? Front Cell Infect Microbiol. 2019;9: 330.

50. Oghumu S, Lezama-Dávila CM, Isaac-Márquez AP, Satoskar AR. Role of chemokines in regulation of immunity against leishmaniasis. Exp Parasitol. 2010;126(3):389-96.

51. Scott $P$, Novais F. Cutaneous leishmaniasis: immune responses in protection and pathogenesis. Nat Rev Immunol. 2016. https://doi.org/10.1038/nri.2016. 72.

52. Kaye $P$, Scott $P$, Leishmaniasis. Complexity at the host-pathogen interface. Nat Rev Microbiol. 2011;9(8):604-15.

53. de Souza Carmo ÉV, Katz S, Barbiéri CL. Neutrophils reduce the parasite burden in Leishmania (Leishmania) amazonensis-infected macrophages. PLoS ONE. 2010;5(11): https://doi.org/10.1371/journal.pone.0013815.

54. Pereira BAS, Alves CR. Immunological characteristics of experimental murine infection with Leishmania (Leishmania) amazonensis. Vet Parasitol. 2008; 158(4):239-55.

55. Awasthi A, Mathur RK, Saha B. Immune response to Leishmania infection. Indian J Med Res. 2004;119(6):238-58. 
56. Martins VT, Lage DP, Duarte MC, Carvalho AMRS, Costa LE, Mendes TAO, Vale DL, Menezes-Souza D, Roatt BM, Tavares CAP, Soto M, Coelho EAF. A recombinant fusion protein displaying murine and human MHC class I- and II-specific epitopes protects against Leishmania amazonensis infection. Cell Immunol. 2017;313:32-42.

57. Horta MF, Mendes BP, Roma EH, Noronha FSM, MacDo JP, Oliveira LS, Duarte MM, Vieira LQ. Reactive oxygen species and nitric oxide in cutaneous leishmaniasis. J Parasitol Res. 2012; ID 203818: https://doi.org/1 $0.1155 / 2012 / 203818$

58. Yen HJ, Hsu SH, Tsai CL. Cytotoxicity and immunological response of gold and silver nanoparticles of different sizes. Small. 2009; 5 (13): 1553-1561.

59. Guimarães ET, Santos LA, Ribeiro dos Santos R, Teixeira MM, dos Santos WLC, Soares MBP. Role of interleukin-4 and prostaglandin E2 in Leishmania amazonensis infection of BALB/C mice. Microbes Infect. 2006;8(5):1219-26.

60. Muniz-Junqueira MI, de Paula-Coelho VN. Meglumine antimonate directly increases phagocytosis, superoxide anion and TNF-a production, but only via TNF-a it indirectly increases nitric oxide production by phagocytes of healthy individuals, in vitro. Int Immunopharmacol. 2008;8(12):1633-8.

61. Frézard F, Demicheli C, Ribeiro RR. Pentavalent antimonials: New perspectives for old drugs. Molecules. 2009;14(7):2317-36.

62. Andres PG, Beck PL, Mizoguchi E, Mizoguchi A, Bhan AK, Dawson T, Kuziel WA, Maeda N, MacDermott RP, Podolsky DK, Reinecker HC. Mice with a Selective Deletion of the CC Chemokine Receptors 5 or 2 Are Protected from Dextran Sodium Sulfate-Mediated Colitis: Lack of CC Chemokine Receptor 5 Expression Results in a NK1.1 + Lymphocyte-Associated Th2Type Immune Response in the Intestin. J Immunol. 2000;164(12):6303-12.

63. Moll H. The role of chemokines and accessory cells in the immunoregulation of cutaneous leishmaniasis. Behring Institute Mitteilungen. 1997;99:73-8.

64. Silveira F. What makes mucosal and anergic diffuse cutaneous leishmaniases so clinically and immunopathogically different? A review in Brazil. Royal Soc Trop Med Hyg. 2019;113:505-16.

65. Mirzaei A, Maleki M, Masoumi E, Maspi N. Review article: A historical review of the role of cytokines involved in leishmaniasis. Cytokine. 2021;145:155297.

\section{Publisher's Note}

Springer Nature remains neutral with regard to jurisdictional claims in published maps and institutional affiliations.

Ready to submit your research? Choose BMC and benefit from:

- fast, convenient online submission

- thorough peer review by experienced researchers in your field

- rapid publication on acceptance

- support for research data, including large and complex data types

- gold Open Access which fosters wider collaboration and increased citations

- maximum visibility for your research: over $100 \mathrm{M}$ website views per year

At $\mathrm{BMC}$, research is always in progress.

Learn more biomedcentral.com/submissions 